\title{
A novel tool for risk assessment related to chemical attacks
}

\author{
Y. Malmén ${ }^{1}$, H. Joki ${ }^{1} \&$ J. S. Jensen ${ }^{2}$ \\ ${ }^{I}$ VTT Technical Research Centre of Finland, Finland \\ ${ }^{2}$ Danish Emergency Management Agency, Denmark
}

\begin{abstract}
There are many elements to chemical, biological, radiological and nuclear (CBRN) crisis management (handheld detectors, decontamination methods, personal protective equipment, standard operating procedures, emergency managements systems, training programmes, etc.). In the ongoing CATO project (EU FP7: 'A comprehensive holistic answer centred on an integrated CBRN toolbox'), these different elements are pulled together in an overall approach to CBRN preparedness and resilience.

CATO proposes a comprehensive holistic answer to CBRN crisis management centred on an integrated CBRN toolbox. CATO starts from the 'puzzle pieces' of the current situation and works within the existing organisational limitations.

In order to complete the 'toolbox puzzle', CATO is also defining and developing new tools. A new risk assessment tool has been developed as part of CATO's Chemical Knowledge Base. This tool tackles one of the key differences between a malicious act and an industrial accident: the unknown identity of the chemical released. The tool allows an unknown chemical agent used in a chemical attack to be categorised based on a limited amount of data. This paper describes the rationale behind the new risk analysis tool and briefly discusses the content given for various chemical groups and how it has been tailored to meet the needs of five user groups: the policy-makers, the incident coordinators, the health care personnel, the responders, and the population.

The development work has been carried out by VTT Technical Research Centre of Finland in cooperation with the Danish Emergency Management Agency (DEMA).

Keywords: C-agents, risk assessment, chemical safety.
\end{abstract}




\section{Introduction}

The security expert community considers the probability of terrorist attacks using chemical, biological, radiological or nuclear (CBRN) material to be increasing. The difficulties of dealing effectively with CBRN crises are manifold. They include [1]:

- Fragmentation: The current approaches and systems are fragmented due to the multiplicity of players and organisational set-ups as well as the lack of effective shared operational pictures and commonly shared information.

- Information waste and fuzziness: The insights produced at the planning stage from threat analysis and scenario development are not readily available during an operational crisis. Much information is theoretically available, but not used.

- Human factors: Current communication means are insufficient for creating awareness of the reality of threats and for 'educating' responders, the general public, and policy-makers in both the appropriate preventive measures and behaviour in the case of CBRN crises.

- Holistic situation assessment: The complexity of a CBRN crisis makes it difficult to maintain an overall picture and assessment of the situation at hand, integrating in real-time the information coming from multiple heterogeneous sources.

- Training: The training is limited by the scarcity of effective simulators and the lack of comprehensive awareness material for the various stakeholders.

- Medical countermeasures: Many treatments are theoretically available, but their efficiency is badly understood and they are often not easy to use.

- Time dimension: CBRN terrorist attacks are difficult to detect because, in many scenarios, they can take several hours or even days to show large-scale effects, or, on the other hand, the damage is immediate giving emergency responders and the authorities no time to react.

- Spatial dimension: Some CBRN terrorism scenarios are characterised by the 'spread' of agents and potentially high mobility of victims in the aftermath of the attack.

- Frequency: The relative rareness to date of CBRN crises makes it difficult to prepare for them and to convince political decision-makers to commit to the necessary investments. Hoaxes and false alarms make it even more difficult to detect the 'real' events.

- Openness: Much information is classified and hence not shareable.

The ongoing CATO project (EU FP7: 'A comprehensive holistic answer centred on an integrated $\mathrm{CBRN}$ toolbox') recognises that many elements for CBRN crisis management exist (detectors, decontamination methods, personal protective equipment, Standard Operating Procedures, emergency management systems, training programmes, etc.). These different elements need to be pulled together in an overall approach to CBRN preparedness and resilience that:

- $\quad$ addresses the overall effectiveness and performance of the response and not just of the individual agencies, 
- can be adapted to different geopolitical, organisational and geographic settings,

- facilitates the multiple usage of the underlying technologies,

- creates an environment supporting progressive learning and enrichment.

CATO proposes a comprehensive holistic answer centred on an integrated CBRN toolbox. To achieve this objective, the CATO consortium has pulled together stakeholders, technology providers and scientific experts. CATO will thereby allow for a huge step in preparedness and resilience to CBRN crises. In order to achieve this objective, CATO is defining and developing tools that allow various organisations to prepare and respond to major disasters in general. One of these tools is a risk assessment tool related to chemical attacks.

\section{Terrorist attacks vs. industrial accidents}

The risk analysis community is well prepared to address potential chemical incidents, in which the hazard is caused by a release of a known substance from a stationary tank, a process installation or even from a transport container. Risk analysis experts are also able to assess the risk caused by a reaction between two substances leading to the formation of, for instance, a toxic gas or a corrosive liquid.

One of the key differences between a malicious act and an industrial accident is in many cases the unknown identity of the chemical released in the terrorist attack. The CATO project addresses two types of terrorist attacks involving a chemical. In the first option, the terrorists attack a chemical installation or a chemical transport. In this case it is likely that the identity of the substance will become known to the emergency responders in minutes. The second way of carrying out a chemical attack is to disperse a hazardous chemical that the terrorists have obtained - or even prepared from less dangerous materials beforehand and transported to the site of the attack. In this case, the time it takes to establish the identity of the $\mathrm{C}$-agent may be unacceptably long, and responders will have to address the situation based on a very limited amount of information.

The number of different toxic industrial chemicals, chemical warfare agents, toxins, and other substances that can be used in a terrorist attack is numerous. Consequently, there is currently no fast and robust handheld device on the market that is able to positively identify all of these substances and that can be expected to be available on an ordinary fire engine or police van. Thus, the information available to the emergency responders may be limited to the symptoms of persons who have been in contact with the substance, the readings from handheld instruments showing whether the substance is flammable, or not, and the odour of the vapour of the substance (although emergency responders are obliged to use breathing apparatus and not to smell the substance). Other indications are the acidity $(\mathrm{pH})$ of the substance and its solubility in water.

An even more difficult situation is at hand, if several substances - or a very impure substance - are involved, or the danger is due to reaction products. Furthermore, if a fire is involved, the spectrum of hazardous substances dispersed into the neighbourhood is even more complex. 


\section{Existing identification tools for unknown chemicals}

Starting from the current situation of 'puzzle pieces' and working within existing organisational limitations, CATO will enable a comprehensive and integrated approach against chemical attacks. In order to complete the 'toolbox puzzle', CATO is also defining and developing new tools. Just as there are currently no easy-to-use detectors available for the emergency responders entering the scene of a terrorist attack, no risk assessment methodology is available, by which the emergency responder or any other party involved can single out the unknown Cagent used. An attempt has therefore been made to develop a new risk assessment tool to be included in CATO's Chemical Knowledge Base. The identification algorithm proposed in CATO, however, is not the first to try to tackle the problem of unknown chemicals. In the following, two existing approaches are presented.

Amongst the emergency responders, the best known of the existing tools designed to identify an unknown chemical based on the physical properties of the substance, the signs and symptoms from exposure to the substance, etc. is probably the Wireless Information System for Emergency Responders (WISER) [2], which has been made available on the Internet by the US National Library of Medicine. WISER is a system designed to assist emergency responders in hazardous material incidents. It provides a wide range of information on hazardous substances, including substance identification support, physical characteristics, human health information, and containment and suppression advice. The substance identification support in WISER is designed to give the user a list of one or more named chemicals out of a database of 438 substances. However, quite frequently, the result is a list of 10 chemicals or more. Furthermore, one wrong answer to one of the questions asked (e.g. the wrong colour) may discard the chemical at hand from the list of options.

The US Department of Health and Human Services has developed the Chemical Hazards Emergency Medical Management (CHEMM) tool [3], part of which is the prototype CHEMM Intelligent Syndromes Tool (CHEMM-IST), a tool for quick identification of the most probable category of chemicals by signs and symptoms of toxicity. CHEMM-IST is an advanced form of FALCON: A Decision Support System for Hazardous Materials Incidents and Terrorism Response. FALCON was developed by J. B. Shreckhise at the James Madison University as an undergraduate thesis project [4]. Working through CHEMMIST will result in a probability for each of the categories assessed as possible based on the answers given to a set of questions (State of alertness?, Syncope?, Pinpoint pupil?, Seizure?, Cardiac signs?, Burning throat/nose?, Wheezing?, Wet lungs/rales?, Sweaty?, Burning chest pain?, Irritated or burning skin?, Eye irritation?, SLUDGE [i.e. salivation, lacrimation, urination, defecation, gastrointestinal, emesis]?, and light-headedness/dizziness?). The categories given in CHEMM-IST are blister agents/vesicants (Lewisite, sulphur mustard, nitrogen mustard, ...), blood/systemic agents a.k.a. knockdown syndrome agents (hydrogen cyanide, arsine, ...), caustics/acids (hydrogen fluoride, ...), choking/lung/pulmonary agents or irritant gas syndrome agents (ammonia, 
chlorine, phosgene, ...), incapacitating agents (Fentanyl, QNB a.k.a. BZ, ...), long-acting anticoagulants (Super warfarin, ...), organophosphorus pesticides and nerve agents (Sarin a.k.a. GB, Soman a.k.a. GD, Tabun a.k.a. GA, VX, ...), and riot control agents/tear gas (chloroacetophenone a.k.a. $\mathrm{CN}$, chloropicrin a.k.a. PS, ...). Biotoxins, metals, organic solvents (acute solvent syndrome agents), toxic alcohols, and vomiting agents are still under development for later release. The CHEMM-IST tool will give medical advice, but no information on, for instance, emergency responders' safety, environmental consequences or the need for evacuation of persons near the place of the incident.

\section{Chemical group identification in CATO}

The approach used in the CATO project, in an attempt to provide the emergency responders and other parties involved with a risk analysis method that gives answers that are more than merely an 'educated guess', is to categorise the chemicals into a manageable number of groups. For each group, a set of instructions is given to the emergency responders, the health care personnel and other parties involved in handling the incident and its victims. An excerpt of the chemical groups, which are based on the properties of the chemical and currently proposed in CATO, is shown in Table 1.

Table 1: Excerpt of the table defining the various chemical groups.

\begin{tabular}{|l|c|c|c|c|c|c|c|c}
\hline \hline \multirow{2}{*}{ Variables } & \multicolumn{7}{c}{ Group \# } & \multicolumn{1}{c}{} \\
\cline { 2 - 10 } & 1 & 2 & 3 & 4 & 5 & 6 & 7 & \\
\hline \hline Gas/vapour & $\bullet$ & $\bullet$ & $\bullet$ & $\bullet$ & & & & \\
\hline Liquid & & & & & $\bullet$ & $\bullet$ & $\bullet$ & \\
\hline Solid & & & & & & & & \\
\hline Toxic & $\bullet$ & $\bullet$ & & & $\bullet$ & $\bullet$ & $\bullet$ & \\
\hline Non-toxic & & & $\bullet$ & $\bullet$ & & & & \\
\hline Flammable & & $\bullet$ & & $\bullet$ & & $\bullet$ & & \\
\hline Non-flammable & $\bullet$ & & $\bullet$ & & $\bullet$ & & $\bullet$ & \\
\hline Water-soluble & & & & & & & $\bullet$ & \\
\hline Water-insoluble & & & & & $\bullet$ & $\bullet$ & & \\
\hline CWA & & & & & & & & \\
\hline
\end{tabular}

This grouping of the chemicals gives rise to at least two key questions: 'Can all chemicals be positively placed into only one category?' and 'what questions must be asked to carry out the categorisation?' In order to answer these questions, the variables used must be defined.

The word 'toxic' is used here to cover also substances that, to a chemist or a toxicologist, are only harmful, irritating or corrosive. Excluded substances are, for instance, carcinogens and other substances, for which the toxic effects appear 
only after a long exposure time. The word 'flammable', in turn, means all substances identified as flammable gases or vapours, when flammable gas detectors are used, and the corresponding liquids.

Obviously, not all chemicals are either completely soluble or completely insoluble in water. Nor can it be assumed that a chemical is only present as a solid, liquid or gas/vapour. Furthermore, some chemicals may be present as solutions (e.g. $\mathrm{HCl}$ in the form of hydrochloric acid and not as a gas) and so on. In other words, no perfect way to categorise chemicals exists. However, until better information about the chemical used in a $\mathrm{C}$-attack is available, it is believed that the safety of the emergency responders and the victims (or potential victims) can be improved by narrowing down the options and by providing instructions on how to deal with the hazards caused by each of the chemical groups, even though there is a risk of error when using the proposed CATO tool.

It is not straightforward to design a set of questions that can be answered by those on the scene of a terrorist attack involving an unknown chemical agent. As mentioned above, the emergency responders basically have three clues to go on: 1) the physical appearance of the substance (solid/liquid/gas, colour, solubility, etc.) (cf. WISER), 2) the symptoms of those affected by the chemical (cf. the CHEMM-IST tool), and 3) the readings of their instruments (flammability, acidity, etc.). Consequently, the reasoning used in the risk analysis has to be based on data obtained from these sources. Should this data not be available, the only remaining option for the responders is to rely on their experience. Even then, the instructions given in CATO for the various chemicals groups should be useful.

\section{The proposed algorithm}

The risk analysis tool should allow an unknown chemical agent (e.g. a chemical warfare agent or an industrial chemical) used in a chemical attack to be categorised based on a limited amount of data.

The first task of the proposed tool is to establish whether the hazard is due to a gas/vapour, a liquid or a solid substance - or a combination of these. In case there is a possibility that the substance is a chemical warfare agent (CWA), a fourth category is given for these substances.

The first question proposed is ' 1 . Is the substance causing the hazard a gas or a vapour?' If yes, the user is asked to go to question 2, if no to question 3 . In the case a volatile liquid is the concern, the user has to consider whether both the liquid phase and the vapour phase are causing the hazard, or only one of these. If both are equally urgent and relevant, then the user has to proceed to both questions 2 and 3.

Question 2 has the following wording: '2. Is there a possibility that the substance is a CWA?' If yes, the user is directed to point 4 and is asked to follow both columns A (gas or vapour) and D (CWA) in the table given in the tool (Table 2). If no: go to point 4 and follow column $\mathrm{A}$ in the table. In reality, many CWAs are neither vapours nor gases when used in a terrorist attack, but aerosols. In order not to make the tool too complex, it is assumed that most emergency 
responders would classify a dispersed CWA as a 'vapour' and would therefore answer yes to question 1 and thus continue to question 2 .

If the answer to question 1 is no (i.e. the substance is not a gas or a vapour), the next question to be answered is ' 3 . Is the substance a liquid or a solution?'. If yes: go to point 4 and follow column B (liquid) in the table. If no: follow column $\mathrm{C}$ (solid) in the table.

Now, the user is asked to answer the questions that are applicable to the column(s) in Table 2 that she or he has been asked to follow based on the three questions given above.

Table 2: Questions used to narrow down the possible chemical groups to which the $\mathrm{C}$-agent may belong.

\begin{tabular}{|c|c|c|c|c|}
\hline & $\begin{array}{c}\text { A } \\
\text { Gas or } \\
\text { vapour }\end{array}$ & $\begin{array}{c}\text { B } \\
\text { Liquid }\end{array}$ & $\begin{array}{c}\mathrm{C} \\
\text { Solid }\end{array}$ & $\begin{array}{c}\mathrm{D} \\
\mathrm{CWA}\end{array}$ \\
\hline $\begin{array}{l}\text { Are there dead persons (due to } \\
\text { suffocation) while all others } \\
\text { have no symptoms? }\end{array}$ & 3,4 & $\mathrm{~N} / \mathrm{A}$ & $\mathrm{N} / \mathrm{A}$ & $\mathrm{N} / \mathrm{A}$ \\
\hline $\begin{array}{l}\text { Do patients have symptoms due } \\
\text { to inhalation of the substance? }\end{array}$ & $1,2,20$ & $\mathrm{~N} / \mathrm{A}$ & $\mathrm{N} / \mathrm{A}$ & 18 \\
\hline Do patients have running eyes? & $1,2,20$ & $\begin{array}{l}7,8,12 \\
19,20\end{array}$ & $\begin{array}{l}14,15 \\
16,17\end{array}$ & 18 \\
\hline $\begin{array}{l}\text { Is the chemical sticking to the } \\
\text { skin, clothes, etc. (not easily } \\
\text { removed with water)? }\end{array}$ & $\mathrm{N} / \mathrm{A}$ & $\begin{array}{l}5,6,9 \\
10,19 \\
20\end{array}$ & $\begin{array}{l}13,15 \\
17\end{array}$ & 18 \\
\hline $\begin{array}{l}\text { Is the chemical easily removed } \\
\text { from skin etc. by rinsing with } \\
\text { water? }\end{array}$ & N/A & $\begin{array}{l}7,8,11 \\
12,19 \\
20\end{array}$ & 14,16 & $\mathrm{~N} / \mathrm{A}$ \\
\hline $\begin{array}{l}\text { Is the gas or vapour flammable } \\
\text { (using a Flammable gas } \\
\text { detector)? }\end{array}$ & $\begin{array}{l}2,4,6 \\
8,10 \\
12,18 \\
19,20\end{array}$ & $\begin{array}{l}6,8,10 \\
12,19 \\
20\end{array}$ & $\mathrm{~N} / \mathrm{A}$ & 18 \\
\hline $\begin{array}{l}\text { Is the gas or vapour non- } \\
\text { flammable (using a Flammable } \\
\text { gas detector)? }\end{array}$ & $\begin{array}{l}1,3,5 \\
7,9,11\end{array}$ & $\begin{array}{l}5,7,9 \\
11\end{array}$ & $\mathrm{~N} / \mathrm{A}$ & 18 \\
\hline
\end{tabular}

The first question in the table is only relevant to gases and vapours and reads: 'Are there dead persons while all others have no symptoms?' The reasoning here is that if there are only bodies at the scene and nobody else has any symptoms at all, then the death is likely to be due to suffocation and not to the toxicity of the released gas or vapour. If the answer to this question is yes, the user notes the numbers in the corresponding box. If no: the gas/vapour is not an asphyxiant or, if it is, this approach has failed. In the case in which only a few persons have been affected by the substance, the assumption that suffocation is the reason for the deaths may be wrong. Furthermore, if there are no 'all others have no 
symptoms' at the scene when the emergency responders arrive (healthy persons are likely to move away from the place of the incident), then the risk algorithm has failed to give a proper answer to this question. However, the following questions may be enough to make up for this failure. It is currently believed that failing to obtain the right answer to this question will in all cases lead to a chemical group, for which the precautions to be taken are more stringent, and, therefore, in most cases, the result is, for instance, a decontamination procedure that would have been unnecessary had the substance causing the deaths been positively identified as non-toxic.

The second question for gases, vapours and CWAs is 'Do patients have symptoms due to inhalation of the substance?' If these symptoms are evident, the substance is likely to be acutely toxic (see definition above) and the given chemical group numbers are recorded by the user. However, if the C-agent causes only delayed symptoms there is a risk that the answer is misleading. This may result in less rigorous decontamination and medical care.

The third question is relevant to all four categories: 'Do patients have running eyes?'. The rationale here is that water-soluble chemicals are more likely to cause tears to be formed than insoluble ones, although it is realised that this is not always the case. A false yes here will lead the user to more stringent procedures than may be necessary (i.e. the user will take conservative actions), while a false no may lead to less appropriate ones. The same is true, if the liquid or solid has not come into contact with the face of the victim(s).

The next question, 'Is the chemical sticking to the skin, clothes, etc. (not easily removed with water)?', is meant to identify chemicals that are insoluble or only slightly soluble in water, while the one after that, 'Is the chemical easily removed from skin etc. by rinsing with water?', should identify substances that are readily soluble in water.

In the next two steps, a reading from a flammability gas detector is needed to establish the flammability of a gas or vapour and the corresponding liquid.

Having answered all relevant questions, the user should, in the best of cases, end up with one number (or two) that is common to all yes answers. Obviously observations by more than one emergency responder will increase the possibility to arrive at the right answer(s). The user is then asked to proceed to the corresponding Chemical Group Safety Card(s). In less favourable situations, this rapidly performed risk analysis exercise may still give the emergency responder a basis for her or his own decisions.

Let us imagine that the yet unknown substance is acrylonitrile and it is the vapour cloud of this substance that is of concern. Then the answer to Question 1 'Is the substance causing the hazard a gas or a vapour?' will be yes, leading us to Question 2, 'Is there a possibility that the substance is a CWA?' The answer to this is likely to be a no, which means that the column to follow in Table 2 is A. The first question in the table is 'Are there dead persons (due to suffocation) while all others have no symptoms?' The obvious answer to this question will be NO. Consequently, there is no Chemical Group Number to be recorded based on this question. The next question is 'Do patients have symptoms due to inhalation of the substance?', and the answer here is yes. The three groups suggested are 1, 
2, and 20. The question about running eyes will be answered by a no, and therefore no Chemical Group Number needs to be recorded. The next question relevant for vapours reads: 'Is the gas or vapour flammable (using a Flammable gas detector)?' The answer to this is yes, and the options given are 2, 4, 6, 8, 10, $12,18,19$, and 20 . A yes to this question automatically gives a no to the last one. The two Group Numbers that are found in both of the recorded lists are 2 and 20. Group number 20 refers to products from chemical fires, and as there is no fire present in the studied case, the remaining Chemical Group Number is 2, i.e. 'Toxic and flammable gases and vapours'. If the liquid phase is also of concern, the analysis should give Number 8 'Toxic, flammable and water-soluble liquid' as the sole outcome.

A second example may be a situation, in which several persons have been sprayed with the toxic liquid epichlorohydrin. In this case, the introductory questions will lead us to Column B 'Liquid' in Table 2. The first question in this column is 'Do patients have running eyes?' and the corresponding answer is yes, giving a list of several possible Chemical Groups: 7, 8, 12, 19, and 20. The question 'Is the chemical sticking to the skin, clothes, etc. (not easily removed with water)?' yields a no, while yes is the answer to the next question 'Is the chemical easily removed from skin etc. by rinsing with water?' Thus numbers 7 , $8,11,12,19$, and 20 are written down. 'Is the gas or vapour flammable (using a Flammable gas detector)?' gives a no, as the ambient temperature is below the flashpoint of the substance. This again means that the last answer will be a yes and the following numbers are noted: 5, 7, 9, and 11. By comparing the three lists of numbers, the only number they have in common is number 7 , i.e. 'Toxic non-flammable and water-soluble liquids', which is the correct number for epichlorohydrin.

\section{The Chemical Group Safety Cards}

For all chemical groups considered in the CATO Knowledge Base, there is information on means to minimise the risk during four distinct phases: the preparedness phase prior to any attacks, the phase, in which a chemical hazard is detected, the response phase during an incident, and the recovery phase after the incident (cf. Table 3). In the following, it is mainly the part of the content meant to be used during the response phase that is discussed. This section also briefly explains how the set of cards has been tailored to meet the needs of five separate user groups: the policy-makers, the incident coordinators, the emergency responders, the health care personnel, and the general public.

On each of the Chemical Group Safety Cards (which may be incorporated as separate 'data fields' and not as a uniform document in the final CATO Knowledge Base), the instructions given for the response phase to the policymakers and the general public are very brief and have only a limited amount of data about the chemical substances. The incident coordinators will receive more guidance about the chemicals and how to organise the response, but the most important Chemical Group Safety Cards are those directed at the emergency response and health care personnel (cf. Table 3). 
Table 3: Excerpt of the content of the Chemical Group Safety Cards.

\begin{tabular}{|c|c|c|}
\hline Phase & Incident Coordinators & Responders \\
\hline 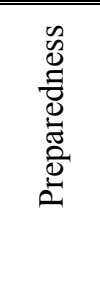 & $\begin{array}{l}\text { - Selection and procurement of } \\
\text { ○ personal protection equipment } \\
\circ \text { portable detectors } \\
\text { ○ other equipment } \\
\text { ○ dispersion modelling tools } \\
\text { - Chemical Knowledge Base } \\
\text { - Training of personnel } \\
\text { - etc. }\end{array}$ & $\begin{array}{l}\text { - Training with personal protection } \\
\text { equipment } \\
\text { - Practising with portable detectors } \\
\text { - Understanding chemical properties } \\
\text { - etc. }\end{array}$ \\
\hline 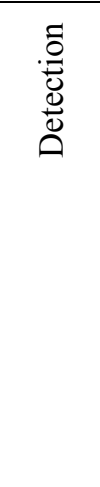 & $\begin{array}{l}\text { - Use of database with chemical } \\
\text { properties } \\
\text { - Identification of the released } \\
\text { chemical } \\
\text { - Selection of portable detectors to } \\
\text { be used } \\
\text { - Selection of personal protection } \\
\text { equipment to be used } \\
\text { - Selection of dispersion modelling } \\
\text { tools to be used } \\
\text { - Use of dispersion modelling tools. } \\
\text { - Setting up cordons } \\
\text { - etc. }\end{array}$ & $\begin{array}{l}\text { - Use of correct personal protection } \\
\text { equipment } \\
\text { - Use of correct portable detectors } \\
\text { - Observation of symptoms in } \\
\text { patients } \\
\text { - Collection of information about the } \\
\text { chemical from the public/truck } \\
\text { driver/plant operator } \\
\text { - etc. }\end{array}$ \\
\hline 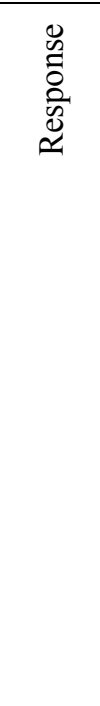 & $\begin{array}{l}\text { - Selection of portable detectors to } \\
\text { be used } \\
\text { - Selection of personal protection } \\
\text { equipment to be used } \\
\text { - Identification of the released } \\
\text { chemical } \\
\text { - Use of database with chemical } \\
\text { properties } \\
\text { - Selection of dispersion modelling } \\
\text { tools to be used } \\
\text { - Use of results from dispersion } \\
\text { models. } \\
\text { - Tactics for limitation of } \\
\text { o the amount of the release } \\
\text { o the hazardous area } \\
\text { - Setting up cordons } \\
\text { - Decontamination of affected } \\
\text { persons } \\
\text { - etc. }\end{array}$ & $\begin{array}{l}\text { - Use of correct personal protection } \\
\text { equipment } \\
\text { - Use of correct portable detectors } \\
\text { - Use of correct response tactics } \\
\text { - Limiting the amount of the release } \\
\text { - Limiting the hazardous area } \\
\text { - Observation of symptoms in } \\
\text { patients } \\
\text { - Collection of information about the } \\
\text { chemical from the public/truck } \\
\text { driver/plant operator } \\
\text { - Decontamination of affected } \\
\text { persons } \\
\text { - etc. }\end{array}$ \\
\hline 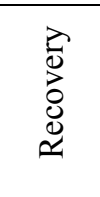 & $\begin{array}{l}\text { - Tactics for decontamination of } \\
\circ \text { affected persons } \\
\circ \text { affected environment } \\
\circ \text { property and equipment } \\
\text { - etc. }\end{array}$ & $\begin{array}{l}\text { - Decontamination of affected } \\
\text { environment } \\
\text { - Decontamination of property and } \\
\text { equipment } \\
\text { - etc. }\end{array}$ \\
\hline
\end{tabular}


On each Chemical Group Safety Card, the guidance given for the response phase considers three separate scenarios involving chemicals: a release of a chemical outdoors, a release indoors, and the contamination of food or drinks with a chemical substance. The instructions given are not only directed at the treatment of the persons affected by the $\mathrm{C}$-agent, but also provide guidance on how the emergency responders and the environment should be protected in order to minimise the consequences of the released substance etc.

As far as possible, a 'bullet point' approach has been used for the guidance during the response phase in order to keep the instructions short. In the Preparedness section, many of the same issues are explained in more detail, as time is not a limiting factor at that stage.

In addition to these Chemical Group Safety Cards, the CATO Knowledge Base will include a set of Safety Cards for some known hazardous chemicals. Furthermore, the Knowledge Base will include guidance related to biological and radiological threats.

\section{Conclusions}

The part of the proposed CATO risk analysis tool described in this paper is, in the main, designed to assist the emergency responders in their task to figure out what actions are needed when responding to a release of an unknown chemical. It consists of a simple algorithm, by which the responder can identify one or two likely chemical groups, to which the chemical belongs. The Chemical Group Safety Cards in turn give the user guidance on how to deal with the situation until more detailed information about the identity of the chemical is known. Like the existing tools, the proposed risk analysis tool is not perfect for all chemical attacks. However, an easy-to-use tool that, in most cases, leads - and not misleads - the user towards a decision that is not merely based on an educated guess is believed to be helpful.

As it is still under development, the CATO risk analysis algorithm and the Chemical Group Safety Cards have not yet been tested in a real situation, and it is therefore too early to assess, whether there may be situations, in which the tool misleads the user in such a way that it results in a higher risk for the contaminated persons, for the emergency responders or health care personnel, or for the environment. So far, it is known that the tool may give the user conservative answers, i.e. instructions that are more stringent than may be necessary for the chemical at hand.

\section{Acknowledgements}

The research leading to these results has received funding from the European Community's Seventh Framework Programme (FP7/2007-2013) under grant agreement $n^{\circ} 261963$ and from the contributing organisations VTT Technical Research Centre of Finland and the Danish Emergency Management Agency (DEMA). 


\section{References}

[1] Rationale. CATO - A comprehensive holistic answer centred on an integrated CBRN toolbox. www.cato-project.eu/page/about-cato/rationale. php

[2] Wireless Information System for Emergency Responders, National Library of Medicine, National Institutes of Health. wiser.nlm.nih.gov

[3] CHEMM Intelligent Syndromes Tool (CHEMM-IST), Chemical Hazards Emergency Medical Management, US Department of Health \& Human Services. chemm.nlm.nih.gov/chemmist.htm

[4] Shreckhise, J.B. Engineering a Medical Response Knowledge Base for FALCON: A Decision Support System for Hazardous Chemical Incidents. A project presented to the Faculty of the College of Integrated Science and Technology, James Madison University, in partial fulfilment of the requirements for the degree Bachelor of Arts, 2006. 